\title{
Organizational and economic-and-legal problems of the transition from the equity residential construction to project financing
}

\author{
Arkady Larionov ${ }^{1, *}$, Magomed Omarov ${ }^{2}$ and Ilya Kostusenko ${ }^{3}$ \\ ${ }^{1}$ Moscow State University of Civil Engineering, Yaroslavskoye shosse 26, Moscow, 129337, Russia \\ ${ }^{2}$ Yaroslav-the-Wise Novgorod State University, Bolshaya Sankt-Peterburgskaya 41, Velikij \\ Novgorod, 173003, Russia \\ ${ }^{3}$ State institute of economics, finance, law, and technology, Roschinskaya 5, Gatchina, 188300, \\ Russia
}

\begin{abstract}
The paper focuses on the features and specificity of the regional market of residential construction in the Moscow region. The authors claim and prove that the solution of complex modern problems of residential construction and the creation of conditions for its further development is directly related to the reasonable application of the existing repertoire of organizational and economic methods of governmental control over this national economy sector. The article represents the authors' opinion on implementing the new laws on equity housing construction that have come into force and their consequences in terms of the well-balanced protection of the rights of citizens participating in equity construction and the economic interests of developers. A possible scenario of premature abandonment of equity construction and the transition to project financing is described.
\end{abstract}

\section{Introduction}

The housing problem remains one of the most pressing socio-economic problems in post-reform and modern Russia. Unfortunately, this problem remains despite the phenomenal feature of the mechanism for implementing its solution. Even a certain defusing of this problem (due to the rule of increasing needs, the full liquidation is impossible) not only creates conditions for the development of residential stock reproduction but also intensifies the functioning and development of the entire system of the national economy in terms of the emerging multiplier effect. That is why the solution of complex modern problems of regional residential construction markets' functioning and creating conditions for their further development is directly connected with the reasonable application of the existing organizational and economic methods of governmental control over this specific regional economy sector.

Considering the economic system as a goal-based integral structure (the composition of the system elements and their bond order), the authors [1] established that getting the output

\footnotetext{
*Corresponding author: proflarionov@mail.ru
} 
(result of functioning) of the system is possible only when various resources, which are necessary for solving the tasks, interact being coordinated on time and in space. Thereat, the elements influence the objects with the help of resources (potential), while the effective interaction of resources is provided by managing this process.

In general, the peculiarity of economic reforms in modern Russia consists in moving towards historical synthesis and in implementing the consistent approach to the assessment of accumulated experience.

The authors reinforce their opinion with the L.I. Abalkin's thesis: "The qualitatively new phenomena that determine the main lines of the changes taking place in the world rely on the accumulated potential of material, intellectual and political culture. The achievements of culture, with few exceptions, do not disappear and form the cumulative effect of social progress gradually accumulating. The richer is this accumulation embodied in experience, knowledge, moral values, democratic institutions and economic structures, the stronger is the foundation for the further progressive development of the society "[2].

When identifying the problems of the functioning of existing and the formation of new institutions that regulate the functioning and development of the residential construction market as a socio-economic system, the authors rely on the main principles of the theory of institutional design proposed by V.L. Tambovtsev [3]. Its essence lies in the fact that the conscious formation of a new institution is a kind of planned cultural innovation. In order to distribute (or "introduce") this innovation successfully, it should correspond to the elements of the cultural space where it is "immerged". If such a correspondence is achieved, the comparative efficiency factor of how the phenomenon being introduced performs one or another function in relation to the already existing objects comes to the fore.

If the requirements of compliance with the environment, "contact" with it are not taken into account, there will be inexplicable situations when an autonomously effective economic institution turns out to be inefficient within the environment that is inadequate to it. If other subjects do not find the proposed "product" - the project of a new institutional arrangement - attractive, the transaction will not succeed and the new institution will not start functioning [4].

\section{Materials and Methods}

Economic laws are one of the initial and basic components of the residential construction market. Each of these laws regulates its area. Together they give not a mechanical sum of laws, not parallel lines, but a new quality involving interaction, involving hierarchy, the supreme role of some laws over others (for example, federal over regional ones) which realizes the priority of the most important relations.

Thus, according to O.V. Inshakova, the law of the economic mechanism functioning consists in the unity and interaction of the opposite sides of the relations generated by this interaction in the transformation functions and the realization of the initial impulses ensuring the equilibrium dynamics of the entity movement through the dynamic equilibrium of the system at all levels.

Moreover, social selection and aiming at unity and balance naturally complement the diversity and redundancy of the opposing elements and structures of the economic mechanism. The equilibrium of the mechanism is determined by the law of continuous mutual denial of the previous stage by each subsequent stage of its movement. It occurs in such a way that each new particular form of the entity changes the entity itself, while each achieved result of the realized goal gives a rise to a new goal and elements, structures, opposites and contradictions that are comparable to this goal. Thus, the economy, as a systematic process, is provided by a mechanism acting as a method of organization and functioning, through which its entity and integrity is developed and reproduced [5]. 
The foregoing allows asserting that the economic mechanism as a transformational process synthesizes the integrated result of interaction between the subjects of regional housing construction markets, at the same time responding to the subjective and objective components. Therefore, the mechanism for the implementation of the studied markets, as well as any economic mechanism, should involve a goal, directions, subjects, objects, legal basis, mechanism itself, diagnostics and correction.

Summarizing the views and results of research of a number of foreign and domestic scientists in the field of institutionalism development [6], it is worth mentioning that institutions create a structure of incentives for public, political or economic exchange. Institutions are both formal laws (constitutions, laws, property rights) and informal rules (traditions, customs, way of life, mentality, codes of behavior). People created institutions in order to maintain order and eliminate uncertainty in exchange. Such institutions coupled with standard restrictions adopted in the economy determined a set of alternatives, therefore defining the costs of production and trade and consequently profitability and chances of being involved in economic activity.

At the same time, it is necessary to recognize that the main problem of the effective functioning of any economic system (in our case, the "regional residential construction market") is the problem of choosing a possible option for its further development: the method of shared-equity construction or project financing.

In a certain sense, the problem of choice is a traditional problem of science and economic practice. The Danish philosopher S. Kierkergor, critic of G. Hegel, noted that the main principle guiding a person is the choice: choosing the one, a person rejects the other.

The problem of choice is indeed a very difficult problem. Therefore, it is quite natural that now all the main participants in the residential construction market (the government, developers, construction companies, commercial banks, as well as participants in shared construction ("equity holders")) found themselves in very difficult choice: continue moving along the "main" road of equity housing construction, or turn to project financing. The authors of this publication tried to answer this question using the example of the Moscow region.

The phenomenon of the Moscow region is that it actually includes two constituent entities of the Russian Federation: the city of Moscow and the Moscow oblast with their utility and transport infrastructure; daily shuttle labor migration; business connections; housing and utilities; collection, recycling and disposal of municipal solid waste, etc.

In the Moscow region (Moscow and the Moscow oblast) residential construction is very active: there are several large property developers, such as GC PIK (Group of companies), "Urban Group", "LSR” Group, GC “A101", "MR Group", GC “Koalko" etc. In particular, according to the Federal State Statistics Service, there are more than 40,000 residential buildings with a total area of 224.8 million square meters in the Russian capital. The provision of square meters per capita in the city of Moscow on 01/01/2018 was 19.8 square meters per person. Therefore, active residential construction is underway in the capital. The most part of new buildings in Moscow are built with investors' money, including numerous shareholders.

Moscow developers put into operation approximately $85 \%$ of the housing each year. The remaining $15 \%$ is built with the municipal budget money, apartments in municipal housing are provided free of charge to privileged categories of citizens. In particular, only from 2000 to 2012 it was built 42 million square meters of housing in Moscow, of which 13 million square meters were erected with the city budget money. Moreover, in the period from 2012 to 2018, the volume of residential construction in Moscow will have been 22.04 million square meters.

According to the government of the Moscow Region, from 2000 to 2015 residential construction in Moscow adjacent areas systematically grew and reached 8.5 million square 
meters. In 2016 about 8 million sq. m. were put into operation. As a result, currently 34.5 square meters accounts per one citizen of the Moscow region. It is one of the highest rates in the country (this index equals 24 square meters on average in Russia). According to the regional program "Dwelling", in 2022 is will be 36.5 sq. meters for each citizen of the Moscow region. Housing should be more accessible: the period required for a family of three persons to purchase a common apartment of 54 square meters should reduce from 4.1 to 3.9 years.

The problem of protecting the rights of citizens participating in equity construction is so relevant because today more than $80 \%$ of the total volume of industrial housing commissioning in Russia involves citizens' funds under equity participation agreements. In particular, in 2016 the volume of investments of Russian citizens in equity construction exceeded 2.8 trillion rubles. The population is actually the main investor in housing construction in our country: about 1 trillion rubles a year equity holders of the Moscow region invest in housing ( 4 trillion rubles per year totally in the country). That is why tens of thousands of hoodwinked investors, who appeared in Russia in recent years (according to the Ministry of Construction of Russia, approximately 200,000 people), significantly increased the degree of tension in society, translating this pressing socio-economic problem into a political plane.

In order to resolve the growing problem of hoodwinked investors in 2016-2017 the legislator has adopted a number of federal laws and regulatory acts aimed at strengthening the protection of the rights of citizens participating in equity construction [7, 8]. The adoption of the mentioned measures not only increased the protection of rights of Russian "shareholders". The authors claim that in terms of housing projects that were started after 01/01/2017, the guarantees of shareholders' rights became absolute.

A special place in the system of measures of the state to guarantee the rights of citizens participating in equity construction belongs to the following occurrences. The first is the refusal to insure the signed equity participation agreement (there are no precedents for insurance companies to compensate at least one insured event in at least one subject of the Russian Federation). The second is the creation of the State donation compensation fund of equity construction [9] as an additional measure to protect the rights of citizens participating in equity construction.

The order of interaction between the developer and the supervisory authority in the new conditions is not "paper-based" at all: the developer must send the project declaration [9] to the supervisory authority in digital form. Such practice in the Moscow region has existed for several years and is demonstrating its effectiveness. In this regard, the authors recommend developers to speed up getting an enhanced digital signature, because the electronic format for submitting such documents will become mandatory.

The legislator introduced serious changes in the design of the equity participation agreement [9]: in addition to the explanatory note, graphic diagrams and drawings, location of the object, etc. should be attached to it (We emphasize that all these materials should be correlated and should correspond to the materials, which the developer will proceed in the project declaration. This allows both a citizen who has signed an equity participation agreement and registered it in Rosreestr, and the supervisory authority to make sure that any particular apartment (flat, studio, parking place) is sold and registered as a property to only one particular citizen, but not repeatedly sold to several beneficiaries).

At the same time, in terms of ensuring the balance of functioning and development of the domestic market of residential construction, the scientific, expert and professional community [10] ambiguously perceives the laws that came into force.

In this regard, the idea that the increased protection of the rights of citizens participating in equity construction at the institutional level was at the expense of pinching the economic interests of developers (other major market participants) is currently one of the most 
discussed on all major platforms of the country. These platforms are the relevant committees of the State Duma and the Federation Council of the Russian Federation, the Ministry of Construction of the Russian Federation, the National Association of Builders, the National Association of housing developers, the Moscow Investors Club, Association of developers of the Moscow region, etc.)

\section{Results}

Not denigrating the importance of the hoodwinked investor problem (unfortunately, such a trouble is peculiar not only to the Moscow region, but also to thousands of Russian families in different constituent entities of the Russian Federation), the authors share the opinion of the professional community on the already approved federal law version on the state compensation fund [11].

First, certain provisions of this law destroy the institutional framework of residential construction and disrupt the implementation of most part of investment and construction projects in the housing sector. The implementation of this law may lead to unintentional bankruptcy and the subsequent liquidation of most part of developers (primarily, those related to small and medium-sized businesses); to the reduction of housing commissioning by large development companies and consequentially to the significant increase in its cost; to massive reduction of workers in organizations of the construction complex (increasing of unemployment degree in the country); to disrupting of the implementation of federal, regional and municipal housing projects and programs.

In particular, among the innovations that destroy "the rules of the game", which were made by legislators and became customary for developers, there is a discrepancy between the new standards and the existing cost structure of developers. For example, the professional community considers unmanageable the limit of expenses for services of a commercial bank, salary for employees, expenses for advertising (promotion of the project), compensation for services of the management company, payments to resourcesupplying organizations (utilities), rent, communication services (no more than $10 \%$ of the project construction cost) that was set by the legislator.

The authors could present a number of other insufficiently substantiated innovations from the legislator aimed at strengthening the protection of the rights of equity construction participants ("shareholders") and tightening the "rules of the game" for developers (Particularly, in terms of market destabilization, the authors consider it risky for developers to become dependent on authorized commercial banks endowed by the legislator with the possibility of initiating a procedure of developer's bankruptcy. Such situation becomes possible, since the bank is obliged to notify the State Compensation Fund of equity construction about each attempt to make a payment that does not correspond to the intended purpose. Moreover, the situation can be exacerbated by the double banking control on work with escrow accounts and the insufficient number of specialists in the banking construction control on the market). However, all the above adds up to the conclusion that the problem of hoodwinked investors of projects started after 01/01/2017 has been resolved. Unfortunately, this happened at the expense of economic interests and activity safety of developers.

Therefore, in order to ensure a balance between the economic interests of developers and the rights of citizens participating in equity construction, the professional community in 2017 proposed to make specific changes in the existing Federal Law-218 of July 29, 2017:

- keep the volume of reporting information provided by the developer to the supervising authority established by law (this will protect the legal rights of citizens), but reduce the number of agencies to which developers must provide such information; 
- exclude the possibility of extrajudicial temporary interruption of the activities of developers by regulatory authorities;

- raise a prohibition of developer participation in holding the property of non-profit organizations (allow participation at least in self-regulatory organizations and developers associations);

- exclude the established limit of $10 \%$ for labor compensation, rent, communication services, advertising, payment for the management company, a commercial bank;

- to regulate the procedure of bank control over the activity of the developer, providing the responsibility for the operations not only of the developer, but also of the authorized commercial bank, putting them in at least equal conditions;

- keep the possibility of banning the profession, but only in cases where the developer's bankruptcy resulted in the failure to fulfill its obligations towards participants in equity construction [12].

Unfortunately, the Ministry of Construction of Russia have missed not only the abovementioned problems of the residential construction market, but also the insightful proposals of the professional community of developers to ensure a balanced protection of the rights of "shareholders" and their economic interests. The before-mentioned body actually ignored all the positive things that have been accumulated in the country over the years of implementation of the legislation on equity residential construction (the number of erected apartment residential buildings, accumulated experience, the created economic and legal field, and certain proposals for its improvement).

The authors make this conclusion because at the end of 2017, the Ministry of Construction of Russia set the housing market participants with a fundamentally different strategic direction for the development of this segment of the national economy, proposing the idea of project financing to the authorities.

AO "AIJK" (together with the Government and the Central Bank of the Russian Federation) is one of the developers of a roadmap for a staged transition from attraction of citizens' capital to other forms of housing finance. Thus, according to one of the developers (V. Shlepov, financial director of AO "AIJK"), the existing model of residential construction has undergone internal changes over the past year. In particular, the law was adopted on the Fund for the Protection of the Rights of Citizens-Participants in Equity Construction. Moreover, on January 1, 2017, a new set of requirements for developers in terms of financial support, own funds, control mechanisms, bank escorts, etc. came into force. The roadmap implies refusing the direct attraction of funds by developers from citizens and replacing these funds with project financing of banks within three years.

V. Shlepov believes that developers will lose the opportunity to attract funds from unqualified investors, which are the majority of individuals, but will be able to take these funds from professional market participants - banks. Thus, a citizen will no longer bear the risk of equity construction, which he or she often could not even assess [13].

The results of studying Russian and world practice indicate that the implementation of any construction project requires very significant financial resources. At the same time, in Western countries there are certain proportions of investment in the construction sector: $2 / 3$ of investments go through bank project financing, $1 / 3$ is companies' own funds. In the particular Moscow region, as in the entire Russia, few developers can meet such requirements due to their difficult current financial situation.

Of course, the supporters of project financing with their identified ratios are correct - it is senseless to argue with facts. The project financing provides more guarantees for shareholders than in the case of equity residential construction. Another issue is how correctly other supporters of project financing understand other aspects of investment and construction activity, which is no less important for modern Russian conditions. 
Thus, according to B. Skupov's data, in Russia it is population who invests in construction, participating in the share construction and carrying out individual construction, or it is directly the budget and state corporations, or business, but in little values. He also argues that the sources of financing for the Russian construction activities are not very diverse, while their availability has decreased significantly in the last three years. In addition, the process of financing the construction complex does not have a systemic nature; it develops spontaneously and practically without taking into account the strategic objectives of the development of the state [14].

In this regard, the authors of this publication have a question: where will modern developers and construction companies find "long" cheap loans for construction of multiapartment houses if the legislator refuse to share construction and transfer them to project financing? Amid ongoing economic sanctions against Russia and a high (overwhelming) refinancing rate.

Due to the depreciation of the ruble, when using foreign components and raw materials in domestic enterprises of the construction and construction materials industry, the cost of housing construction has increased. Under these conditions, most developers are going to reduce their profitability, having to reduce the rate of profit.

It seems that reducing the rate of profit for developers and builders is good for the housing market in general, and for buyers of residential real estate in particular: apartments are becoming cheaper. Nevertheless, this is a very serious problem directly related to the destabilization of the construction industry. The builders will not be able to reduce the rate of profit permanently, unless they sell finished houses below the cost of its production. Moreover, according to experts, a very large part of developers and construction companies are already on the verge of survival and are seriously considering transferring the remaining capital to other sectors of the national economy (this does not include those who have already gone bankrupt or are close to this stage).

\section{Discussions}

Of course, the transition to project financing will largely protect the rights of shareholders (who will be sufficiently protected, when all the prescribed rules of the Federal Law-218 of July 29, 2017 come into force). However, the question arises to the Ministry of Construction of Russia: "Why strengthen the rights of those who are already protected and do not need additional protection? Moreover, at the expense of those who create multiapartment residential houses?"

In this regard, the authors believe that a sharp transfer of the domestic construction industry (under the unreasonable excuse of additional protection of shareholders) to project financing under the absence of "long" financial resources accessible to developers and construction companies is detrimental to the residential construction market.

Everyone knows that for the effective functioning and development of any organism (including socio-economic ones) it is necessary to consume various nutrients in sufficient amounts through the blood circulatory system. In our case, the "blood circulatory system" of housing construction over the past decade has implied "long" cheap foreign loans, as well as relatively affordable mortgage loans and, most importantly, personal savings of Russian citizens. We emphasize that the Moscow region was prosperous in this matter: in recent years, everything was fine with investments in the development business of Moscow and the Moscow region.

Then as now, this channel is blocked by the legislator (under the pretext of additional protection of citizens who need to improve their living conditions) by refusal of share construction and transfer housing construction to the project financing. This happens under conditions of falling effective demand not only for the purchase or construction of housing 
in multi-apartment buildings, but even for housing credits. Therefore, according to D. Usmanov, the commercial director of the Group of Companies GC MIC, one of the most fundamental drivers of the market is the income of the population. He believes that people should have available funds to buy housing. The whole economy should work for this purpose. In the meantime, Russians' revenues have been falling for four years [15].

Of course, the authors agree with opponents of equity construction that this method of financing was vulnerable to cheat and in this regard, we share the assessment of B. Skupov presented below. He quite rightly asserts that the most typical cases are when the developer collects money and disappears with them in the Cyprus offshore region, leaving the construction site and shareholders. Quite often, there was an inappropriate spending of money by investing money instead of building a residential building in a pyramid, like MMM. Finally, the so-called developers simply did not know how to build and could not present anything to their client.

Investor S. Polonsky is even more judgmental in his assessments. He supposes that project financing will lead to a rise in housing prices by at least $20 \%$. He criticized the actions of the regulator, calling such changes in the housing finance mechanism "nonsense" at the peak of the crisis, as well as he called transferring all the risks to the discredited banking sector. He believes that the transition to project financing will destroy the market. Small and medium-sized companies will disappear, and large developers will be able to take loans only in 3-5 large banks, because the rest simply will not pass by the size of capital (the average project of one hundred thousand square meters involves financing of about one hundred million dollars).

\section{Conclusion}

Let us drew the balance of the comparative analysis of equity financing of housing construction in Federal Law FZ-218 edition of 07/29/2017 and project financing.

First, it should be admitted that the financial frauds of dishonest developers and the appearance of two hundred thousand hoodwinked investors is a weighty argument of opponents of equity construction, and the authors cannot disagree with that. Nevertheless, this happened only when equity participation agreement was signed, before the new legislation on shared housing financing came into force on January 1, 2017.

Secondly, both federal and regional executive authorities should continue to solve the problem of hoodwinked investors. Particularly, the authorities of the Moscow region is solving this problem according to their capabilities. There are some positive results: the total number of hoodwinked investors is reduced every year.

Thirdly, the problems of equity construction on objects, the first pre-payment facilities for which were concluded before 01/01/2017 (the "old" legislation) and after this date (norms FL-214 dated July 3, 2016 and FL-218 dated July 29, 2017) should not be mixed. The authors emphasize that the above-mentioned innovations of "armor" for the "old" shareholders protect only those, who signed the equity participation agreement after $01 / 01 / 2017$. Therefore, new legislation on equity construction as well as project financing cannot solve the problem of the already hoodwinked investors.

Fifth, the Ministry of Construction of Russia, the Governments of Moscow, the Moscow Region and other subjects of the Russian Federation, when implementing and adjusting the "roadmap" of refusing share residential construction and switching to project financing, should consider the following:

- since the current legislation on equity residential construction has now defended the rights of shareholders at the absolute level, a moratorium should be arranged for at least 2-3 years for further lawmaking in this area; 
- equity construction continues to be the main source of housing finance in the Moscow region and in other constituent entities of the Russian Federation, therefore a complete abandonment of it in the next 3-5 years is fraught with an investment collapse of housing construction;

- the premature transition of residential construction to project financing under the modern Russian conditions can trigger the following negative scenario: mass bankruptcy of developers, freezing of a significant number of housing projects, reduction of supply volumes, increase in prices for finished objects in 2-3 years due to loans for developers, which ultimately will be allocated to the cost of construction and significantly increase the selling prices for new buildings.

\section{References}

1. T. Simankina, M. Romanovich, O. Tsvetkov, MATEC Web of Conferences 53, 01054 (2016)

2. V. Kvint, Strategy for the Global Market: Theory and Practical Applications (New York, 2015)

3. Ju. Panibratov, A. Larionov, World Applied Sciences Journal, Problems of Architecture and Construction 23, 144-148 (2013)

4. A. Larionov, Yu. Larionova, MATEC Web of Conferences 106, 08032 (2017)

5. A. Larionov, MATEC Web of Conferences 106, 09022 (2017)

6. A. Larionov, MATEC Web of Conferences 170, 01103 (2018)

7. A. Larionov, L. Metechko, A. Davydov, D. Davydov, MATEC Web of Conferences 193, 04027 (2018)

8. V. Kankhva, E3S Web of Conferences 33 (2018) doi: 10.1051/e3sconf/20183301036

9. E. Nezhnikova, O. Papelniuk, A. Gorokhova, International Journal of Energy Economics and Policy 8(1), 203-211 (2018)

10. M. Rafiei, H. Adeli, Structural Design of Tall and Special Buildings (2016)

11. A. Aminmansour, K. Moon, Journal of Architectural Engineering 16(2), 47-53 (2010)

12. B. Furlong, S. De Silva, K. Gan, L. Guthrie, R. Considine, Journal of Environmental Management 191, 83-95 (2017)

13. K. Anagnostis, K. Alexios, Procedia Economics and Finance 9, 120-132 (2014)

14. H. Jang, S. Choi, W. Kim, C. Chang, KSCE Journal of Civil Engineering 16(7), 11151122 (2012)

15. O. Alshamrani, K. Galal, S. Alkass, Building and Environment 80, 61-70 (2014)

16. D.N. Silka, World Applied Sciences Journal 31, 148-150 (2014) 